\title{
Behavioral Treatment for Veterans with Obesity: 24-Month Weight Outcomes from the ASPIRE-VA Small Changes Randomized Trial
}

\author{
Lesley D. Lutes, $P h D^{7}$, Laura J. Damschroder, $M S, M P H^{2}$, Robin Masheb, $P h D^{3}$, \\ Hyungjin Myra Kim, ScD ${ }^{2,4}$, Leah Gillon, MSW², Robert G. Holleman, MPH², David E. Goodrich, EdD², \\ Julie C. Lowery, PhD², Carol Janney, $P h D^{5}$, Susan Kirsh, MD, MPH', and Caroline R. Richardson, $M^{7}$ \\ 'Department of Psychology, University of British Columbia, Kelowna, BC, Canada; ${ }^{2}$ VA Center for Clinical Management Research, VA Ann Arbor \\ Healthcare System, Ann Arbor, MI, USA; ${ }^{3}$ Department of Psychiatry, Yale School of Medicine, New Haven, CT, USA; ${ }^{4}$ Center for Statistical \\ Consultation and Research, University of Michigan, Ann Arbor, MI, USA; ${ }^{5}$ Department of Epidemiology and Biostatistics, Michigan State University \\ College of Human Medicine, Midland Regional Campus, Midland, MI, USA; 'ouis Stokes Veterans Affairs Medical Center, Cleveland, OH, USA; \\ ${ }^{7}$ Department of Family Medicine, University of Michigan, Ann Arbor, MI, USA.
}

\begin{abstract}
BACKGROUND: Small Changes (SC) is a weight management approach that demonstrated superior 12-month outcomes compared to the existing MOVE! ${ }^{\circledR}$ Weight Management Program at two Veterans Affairs (VA) sites. However, approaches are needed to help graduates of treatment continue to lose or maintain their weight over the longer term. OBJECTIVE: The purpose of the present study was to examine the effectiveness of a second year of lowintensity SC support compared to support offered by the usual care MOVE! programs.
\end{abstract}

DESIGN: Following participation in the year-long Aspiring to Lifelong Health in VA (ASPIRE-VA) randomized controlled trial, participants were invited to extend their participation in their assigned program for another year. Three programs were extended to include six SC sessions delivered via telephone (ASPIRE-Phone) or an in-person group (ASPIRE-Group), or 12 sessions offered by the MOVE! programs.

PARTICIPANTS: Three hundred thirty-two overweight/ obese veterans who consented to extend their participation in the ASPIRE-VA trial by an additional year.

MAIN MEASURES: Twenty-four-month weight change (kg).

KEY RESULTS: Twenty-four months after baseline, participants in all three groups had modest weight loss $(-1.40 \mathrm{~kg}$ [ -2.61 to -0.18$]$ in the ASPIRE-Group, $-2.13 \mathrm{~kg}[-3.43$ to $-0.83]$ in ASPIRE-Phone, and $-1.78 \mathrm{~kg}[-3.07$ to -0.49$]$ in MOVE!), with no significant differences among the three groups. Exploratory post hoc analyses revealed that participants diagnosed with diabetes initially benefited from the ASPIRE-Group program (-2.6 kg [-4.37 to 0.83]), but experienced significant weight regain during the second year (+2.8 kg [0.92-4.69]) compared to those without diabetes.

CONCLUSIONS: Participants in all three programs lost weight and maintained a statistically significant, though clinically modest, amount of weight loss over a 24-month period. Although participants in the ASPIRE-Group initially had greater weight loss, treatment was not sufficient to sustain weight loss through the second year, particularly in veterans with diabetes. Consistent, continuouscare treatment is needed to address obesity in the VA.

KEY WORDS: veterans; obesity; behavioral medicine; weight management; clinical trials.

Published online March 7, 2017
J Gen Intern Med 32(Suppl 1):S40-S7

DOI: $10.1007 / \mathrm{s} 11606-017-3987-0$

(c) Society of General Internal Medicine 2017

\section{INTRODUCTION}

While obesity remains at historically high levels in the US adult population, ${ }^{1,2,3}$ rates are even higher among veterans. Nationwide, $32 \%$ of veterans live with obesity, ${ }^{4}$ and for those who have received care in the Veterans Health Administration (VHA), the rate is even higher, at $41 \%{ }^{5}$ The Department of Veterans Affairs (VA) provides healthcare to patients that are predominantly male, older, of lower socioeconomic status, and often burdened by multiple physical and mental health comorbidities compared to patients in other healthcare systems, which creates challenges for obesity treatment. ${ }^{6}$

In 2006, the VA introduced the MOVE! ${ }^{\circledR}$ Weight Management Program to meet the urgent need to address obesity and its subsequent effects on health. ${ }^{4,7,8}$ While MOVE! encompasses multi-level behavioral interventions consisting of treatments delivered in different modalities (e.g., group, individual, telehealth), the majority of treatment $(72 \%)$ is delivered via inperson group sessions. ${ }^{9}$ Despite evidence of weight gain prior to participation, ${ }^{10,11}$ single-site and system-wide analyses of participant outcomes have consistently revealed significant, though modest, weight loss at 6 and 12 months. ${ }^{9,10,12}$

However, the problem of long-term weight loss maintenance has been argued as the greatest challenge in treating obesity. ${ }^{13}$ Though clinically significant weight loss has been achieved in a sizable portion of participants across many randomized controlled trials, ${ }^{14-16}$ weight loss often peaks at 6-12 months, with subsequent weight regain. Successful maintenance of weight loss is generally defined as minimal weight gain for at least 12 months after intensive treatment. ${ }^{17}$ A systematic review ${ }^{18}$ and other trials ${ }^{19}$ have found that patients who received long-term follow-up or "continuous-care" treatment were more likely to retain more of their weight loss over a 24-month period than those who did not receive followup care. 
Small Changes (SC) is an evidence-based treatment approach $^{20-23}$ for addressing obesity that encourages and supports participants in making modest changes to their dietary intake and level of physical activity relative to their current behaviors and attitudes, which differs from other approaches that have prescribed goals. ${ }^{24}$ The Aspiring to Lifelong Health in Veterans Affairs (ASPIRE-VA) trial tested the SC approach among 481 veteran participants in a 12 -month program. ${ }^{25}$ The year prior to enrolling in the trial, participants experienced an average weight gain of $2.7 \mathrm{~kg}$. At enrollment, participants were randomized to 1) group-based delivery of SC (ASPIRE-Group), 2) individual phone-based delivery of SC (ASPIRE-Phone), or 3) the usual care in-person group-based MOVE! program in two VA medical centers in the US Midwest. $^{25}$ Twelve months later, participants in the ASPIREGroup had lost twice the amount of weight $(-2.8 \mathrm{~kg})$ as participants in ASPIRE-Phone or MOVE! $(-1.4 \mathrm{~kg}$ for both groups), and session attendance was markedly higher in the two SC arms compared to MOVE!. ${ }^{26}$

The aim of the current study was to extend the 12-month ASPIRE-VA trial into another year of low-intensity support to examine the impact of SC over the long term in this complex, underserved population compared to the usual care MOVE! program. Additionally, through post hoc exploratory analyses, we sought to identify factors that might impact weight trajectory over 24 months, including diabetes because of its high prevalence among veterans. ${ }^{27,28}$

\section{METHODS}

\section{Study Design}

The full design and rationale of the original ASPIRE-VA weight management study ${ }^{25}$ and 12-month treatment outcomes $^{26}$ are reported elsewhere. In the original trial, participants were randomized to one of three treatment arms (described above) for a period of 1 year. Participants who completed the 12-month assessment were invited to participate in an additional 12 months of treatment. Institutional review was obtained for the original and extended studies at two Midwestern VA medical centers.

\section{Participants and Procedures}

In the initial trial, participants were provider- or self-referred for weight management services and were eligible for the MOVE! program $\left(\mathrm{BMI} \geq 30 \mathrm{~kg} / \mathrm{m}^{2}\right.$, or BMI of $25-30 \mathrm{~kg} / \mathrm{m}^{2}$ and at least one obesity-related health condition). Other inclusion criteria were capacity to consent, reliable access to a telephone, and ability to communicate in English. Exclusion criteria included current enrollment in another weight loss or physical activity trial, inability to complete a 6-min walking test, and pregnancy. Of the 481 participants originally randomized in the trial, $332(69 \%)$ consented to a second year of follow-up treatment (Fig. 1). Enrollment in the first year began in January 2010, and the last of the extended assessments (out to 24 months) were completed in November 2013. Participants received additional remuneration for completing additional assessments at 18 months (\$50) and 24 months (\$50) after their initial enrollment.

\section{Small Changes (SC) Intervention Programs}

The two ASPIRE SC arms were designed based on the SC model of behavior change, ${ }^{24}$ which draws from social-psychological goal-conflict theories and encourages patientchosen behavioral goals, the benefits of which (e.g., weight loss) would accumulate slowly over time. ${ }^{25}$ Participants were encouraged to set new goals only after previous behaviors were successfully maintained.

During the first year, both ASPIRE SC treatment arms consisted in weekly sessions for 3 months, followed by 6 months of biweekly sessions, and then 3 monthly sessions (28 sessions total). Non-clinician lifestyle coaches conducted the ASPIRE SC sessions. Coaches had at least a bachelor's degree and did not possess any specific psychology, behavior change, or coaching training/experience. A licensed clinical psychologist (LDL) and master's-level social worker (LG) facilitated ongoing supervision and feedback based on patient data and supervisor reports. These coaches and the supervision continued in the extended second year.

For the current study, which focuses on the second year, participants were offered the opportunity to continue with their same coach in the same program as during the first year (i.e., phone for ASPIRE-Phone, in-person groups for ASPIREGroup). However, coaching sessions were less frequent; rather than monthly, they were scheduled every other month $(n=6$ sessions). Both SC arms had the same number of sessions, but total contact time was different: phone sessions lasted $20 \mathrm{~min}$ and group sessions lasted $60 \mathrm{~min}$. As in the last 3 months of the first year, sessions consisted in 1) checking in on progress toward patient-selected goals, 2) problem-solving any issues related to barriers and challenges to making dietary and physical activity changes, and 3) setting goals for the following 2 months.

\section{Usual Care: MOVE! Weight Management Program}

In the first year, individuals who were randomized to the MOVE! program had 11-12 weekly sessions delivered by a team of leaders in each of the two study sites. ${ }^{25}$ After completion of the weekly sessions, the sites offered a range of options: quarterly 90 -min or biweekly 60 -min group sessions, repeating the initial series of 11 or 12 weekly sessions, or engaging in other programs (e.g., TeleMOVE, an in-home technology-based program). ${ }^{29}$ These offerings continued, unchanged, into the second year. Study staff contacted MOVE! participants only to obtain consent for participation in the study's second year and to schedule and conduct their 18and 24-month assessments. 


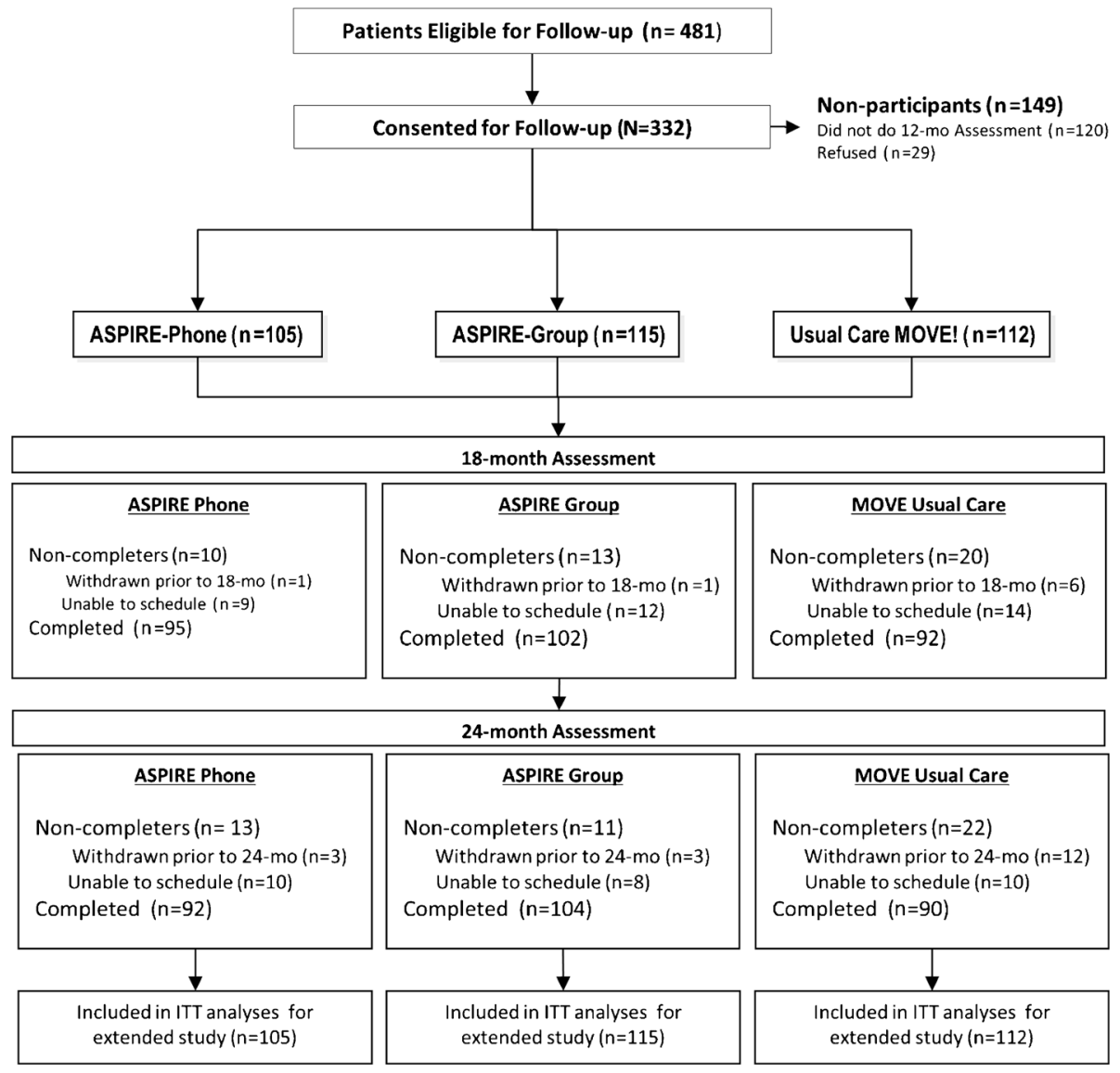

Figure 1 CONSORT diagram of patient flow and retention for follow-up.

\section{Outcome Measure}

The primary outcome for the present study was weight at 24 months, measured as a continuous variable. Results are presented in absolute weight change $(\mathrm{kg})$ from baseline to 3 , 12,18 , and 24 months.

\section{Statistical Analyses}

Analyses were performed in Stata version 13.1 software (StataCorp LP, College Station, TX). The chi-square test and $t$ tests were used to examine differences in baseline characteristics between those who consented $(N=332)$ and those who did not consent to the second follow-up year $(n=149)$. The primary analytic cohort included all participants consenting to participate in the second year of follow-up who continued with the same treatment arm assigned at the start of the first year. We examined treatment engagement across the three intervention arms, and report the mean number of completed sessions by arms. Weight changes across the three arms at each follow-up time were analyzed using linear mixed-effects models with baseline and 3-, 12-, 18-, and 24-month weight as dependent variables. The model included participants as random intercepts to adjust for withinparticipant correlation of the repeated measures, fixed predictors of study arm, 3-, 12-, 18-, and 24-month time indicators, and time by study arm indicators. This model enables the inclusion of all participants with at least one weight measure at any time point.
Expected weight changes at follow-up times from baseline were estimated using parameter estimates from the model.

Furthermore, as diabetes prevalance is high in Veterans, and has been identified as a potential moderator of weight outcomes, exploratory post-hoc analyses were conducted to assess the role of diabetes in long-term weight change. ${ }^{25-28}$ The analytic model described above was extended by adding the interaction terms of the potential moderator by intervention arm indicators by follow-up time.

\section{RESULTS}

\section{Study Participants}

Of the 481 participants who enrolled in the initial 12-month program, 332 consented to participate in the 24-month followup. These individuals $(N=332)$ tended to be older than those who did not continue into the second year $(n=149$; Table 1), but were otherwise comparable. Individuals participating in the second year were predominately middle-aged (mean age $=55.98$ ) men $(85.5 \%$ ) with moderate obesity (mean $\mathrm{BMI}=36.2$ ). They were ethnically diverse, with $42 \%$ non-white and $44 \%$ reporting less than $\$ 20,000$ annual income, and based on electronic medical health record data, most had multiple physical and mental health diagnoses (Table 1). Table 2 shows baseline characteristics by arm for the 332 participants who consented to the second year. 
Table 1 Baseline Characteristics of the ASPIRE-VA Participants in Initial and Follow-Up Treatment

\begin{tabular}{|c|c|c|c|c|}
\hline Characteristics & Total $(n=481)$ & Follow-up Yes $(n=332)$ & Follow-up No $(n=149)$ & $p$ values \\
\hline Age, $M(\mathrm{SD})$ & $55.0(10.0)$ & $55.98(9.5)$ & $52.69(10.7)$ & $<0.001$ \\
\hline BMI $\left(\mathrm{kg} / \mathrm{m}^{2}\right)$ & $36.5(6.2)$ & $36.2(6.0)$ & $37.1(6.7)$ & 0.12 \\
\hline Male & $409(85.0)$ & $284(85.5)$ & $125(83.9)$ & 0.64 \\
\hline \multicolumn{5}{|l|}{ Race/ethnicity } \\
\hline Black & $196(40.7)$ & $135(40.7)$ & $61(40.9)$ & \multirow{3}{*}{0.06} \\
\hline White & $276(57.4)$ & $194(58.43)$ & $82(55.03)$ & \\
\hline Other & $9(1.9)$ & $3(0.90)$ & $6(4.027)$ & \\
\hline \multicolumn{5}{|l|}{ Education, years } \\
\hline$<13$ & $108(22.5)$ & $73(22.0)$ & $35(23.5)$ & \multirow{4}{*}{0.46} \\
\hline $13-16$ & $254(52.8)$ & $174(52.4)$ & $80(53.7)$ & \\
\hline$\geq 16$ & $108(22.5)$ & $75(22.6)$ & $33(22.2)$ & \\
\hline $\bar{M}$ Missing & $11(2.3)$ & $10(3.0)$ & $1(0.7)$ & \\
\hline Income $<\$ 20,000$ & $196(42.9)$ & 137 (43.9) & $59(40.7)$ & 0.52 \\
\hline Health-related disability & $249(55.2)$ & $166(54.1)$ & $83(57.6)$ & 0.48 \\
\hline Charlson Comorbidity Index, M (SD) & $1.1(1.5)$ & $1.2(1.5)$ & $0.98(1.4)$ & 0.16 \\
\hline Depression & $156(32.5)$ & $105(31.7)$ & $51(34.2)$ & 0.59 \\
\hline PTSD & $76(15.8)$ & $57(17.2)$ & $19(12.8)$ & 0.22 \\
\hline Serious mental illness & $31(6.5)$ & $18(5.4)$ & $13(8.7)$ & 0.18 \\
\hline Substance use disorder & $82(17.0)$ & $57(17.17)$ & $25(16.78)$ & 0.90 \\
\hline Diabetes & $177(36.8)$ & $122(36.8)$ & $55(36.9)$ & 0.97 \\
\hline Hypertension & $319(66.3)$ & $226(68.1)$ & $93(62.4)$ & 0.23 \\
\hline Hypercholesterolemia & $244(50.8)$ & $171(51.51)$ & 73 (48.99) & 0.61 \\
\hline \multicolumn{5}{|l|}{ EQ-5D pain } \\
\hline None & $89(18.8)$ & $64(19.6)$ & $25(17.0)$ & \multirow{3}{*}{0.62} \\
\hline Moderate & $323(68.3)$ & $218(66.9)$ & $105(71.4)$ & \\
\hline Severe & $61(12.9)$ & $44(13.5)$ & $17(11.6)$ & \\
\hline \multicolumn{5}{|l|}{ Site } \\
\hline Site 1 & $239(49.7)$ & $167(50.3)$ & $72(48.3)$ & \multirow[t]{2}{*}{0.69} \\
\hline Site 2 & $242(50.3)$ & $165(49.7)$ & 77 (51.7) & \\
\hline
\end{tabular}

\section{Weight Change Over 24 Months}

We examined weight change using age-adjusted and unadjusted models, which yielded similar results. The findings from unadjusted models are presented. All three intervention groups showed significant weight loss 24 months after baseline; weight change for this period was comparable across the three programs, with mean change of $-1.40 \mathrm{~kg}$ in ASPIRE-Group, $-2.13 \mathrm{~kg}$ in ASPIRE-Phone, and $-1.78 \mathrm{~kg}$ in MOVE!

Table 2 Baseline Characteristics of the ASPIRE-VA Participants in Extended 2nd Year of Treatment by Arm

\begin{tabular}{|c|c|c|c|c|}
\hline Characteristics & ASPIRE-Phone $(n=105)$ & ASPIRE-Group $(n=115)$ & MOVE! $(n=112)$ & $p$ values \\
\hline Age, M (SD) & $56.9(9.0)$ & $55.8(9.4)$ & $55.3(10.1)$ & 0.45 \\
\hline $\mathrm{BMI}\left(\mathrm{kg} / \mathrm{m}^{2}\right), \mathrm{M}(\mathrm{SD})$ & $35.5(5.6)$ & $36.4(6.0)$ & $36.5(6.4)$ & 0.38 \\
\hline Male $(\%)$ & $87(83.0)$ & $98(85.2)$ & $99(88.4)$ & 0.51 \\
\hline \multicolumn{5}{|l|}{ Race/ethnicity (\%) } \\
\hline Black & $43(41.0)$ & $50(43.4)$ & $42(37.5)$ & \multirow{3}{*}{0.93} \\
\hline White & $61(58.0)$ & $64(55.7)$ & 69 (61.6) & \\
\hline Other & $1(1.0)$ & $1(0.9)$ & $1(0.9)$ & \\
\hline \multicolumn{5}{|l|}{ Education, years (\%) } \\
\hline$<13$ & $24(22.9)$ & $25(21.7)$ & $24(21.4)$ & \multirow{4}{*}{0.29} \\
\hline $13-16$ & $49(46.7)$ & $59(51.3)$ & $66(58.9)$ & \\
\hline$\geq 16$ & $29(27.6)$ & $29(25.2)$ & $17(15.2)$ & \\
\hline Missing & $3(2.9)$ & $2(1.7)$ & $5(4.5)$ & \\
\hline Income $<\$ 20,000(\%) *$ & $36(34.3)$ & $52(45.2)$ & $49(43.8)$ & 0.10 \\
\hline Health-related disability (\%) & $41(39.0)$ & $60(52.2)$ & $65(58.0)$ & 0.01 \\
\hline Charlson Comorbidity Index, M (SD) & $1.1(1.3)$ & $1.2(1.5)$ & $1.2(1.6)$ & 0.11 \\
\hline Depression $(\%)$ & $20(19.0)$ & $41(35.7)$ & $44(39.3)$ & 0.003 \\
\hline PTSD (\%) & $12(11.4)$ & $25(21.7)$ & $20(17.9)$ & 0.12 \\
\hline Serious mental illness $(\%)$ & $6(5.7)$ & $4(3.5)$ & $8(7.1)$ & 0.46 \\
\hline Substance use disorder (\%) & $6(5.7)$ & $13(11.3)$ & $38(33.9)$ & $<0.001$ \\
\hline Diabetes $(\%)$ & $34(32.4)$ & $48(41.7)$ & $40(35.7)$ & 0.34 \\
\hline Hypertension (\%) & $70(66.7)$ & $79(68.7)$ & $77(68.8)$ & 0.93 \\
\hline Hypercholesterolemia (\%) & $48(45.7)$ & $68(59.1)$ & $55(49.1)$ & 0.11 \\
\hline \multicolumn{5}{|l|}{ EQ-5D pain $(\%)^{\dagger}$} \\
\hline None & $23(21.9)$ & $26(22.6)$ & $15(13.4)$ & \multirow{3}{*}{0.40} \\
\hline Moderate & $67(63.8)$ & $73(63.5)$ & $78(69.6)$ & \\
\hline Severe & 12 (11.4) & $15(13.0)$ & $17(15.2)$ & \\
\hline \multicolumn{5}{|l|}{ Site $(\%)$} \\
\hline Site 1 & $54(51.4)$ & $51(44.3)$ & $62(55.4)$ & \multirow{2}{*}{0.24} \\
\hline Site 2 & $51(48.6)$ & $64(55.7)$ & $50(44.6)$ & \\
\hline
\end{tabular}

*20 Patients with missing values

${ }^{\dagger} 6$ Patients with missing values 
(Table 3). Results from secondary analyses, taking an intention-to-treat approach that included all 481 participants from the ASPIRE-VA trial (data not shown), were consistent with the findings based on the primary analytic cohort $(n=332)$.

Post hoc analyses exploring weight change patterns over the 2-year intervention period revealed that between 12 and 24 months, participants in the ASPIRE-Phone and MOVE! groups maintained or continued their weight loss, but participants in the ASPIRE-Group experienced significant weight regain (Fig. 2). Further exploratory analyses revealed that participants with diabetes had a different weight trajectory in the second year across the three arms (chi-square $=24.37$, $p<0.001)$. Specifically, participants with diabetes who were in the ASPIRE-Group arm had significant weight loss during the first year of treatment $(-2.6 \mathrm{~kg} ; 95 \% \mathrm{CI}:-4.37,-0.83)$, adjusting for age, but in the second year they had significant weight gain (+2.8 kg, 95\% CI: 0.92, 4.69; Fig. 3).

\section{Engagement}

Over 24 months, participants in the two ASPIRE SC programs completed more sessions than MOVE! participants: 18.9 sessions (95\% CI: 17.0-20.9) for ASPIRE-Group, 20.8 (95\% CI: 18.8-22.8) for ASPIRE-Phone, and 8.6 (95\% CI: 6.9-10.3) for MOVE!. In the second year, participants in ASPIREGroup (2.6; 95\% CI: 2.2-3.0), ASPIRE-Phone (2.4; 95\% CI: 2.0-2.9), and MOVE! (2.3; 95\% CI: 1.4-3.3) completed a comparable number of sessions, indicating that engagement differences were accrued during the first year.

\section{DISCUSSION}

To our knowledge, this is the first study to examine longerterm weight loss treatment in the VA and in a sample of predominantly middle-aged and ethnically diverse male veterans with multiple chronic behavioral and health conditions. Results from the present study show that, while all three groups experienced weight loss 2 years after baseline, the ASPIRE treatment was insufficient to maintain the higher weight loss seen at 12 months in the ASPIRE-Group arm compared to the other two programs: by 24 months, all three programs had comparable weight loss.

These findings have implications for the design of VA population-based services to support the long-term healthy weight management of their veterans. Perhaps the most provocative questions raised by these findings concern the level and type of continuous-care obesity treatments that are needed to better serve this medically complex population. Little is known about which treatment approaches and intensities are optimal for continued weight loss. ${ }^{8,30-32}$ One trial that tested three approaches, one of which was in-person monthly contact, found that on average, all participants in all three approaches gained weight after having lost at least $4 \mathrm{~kg}$ in the prior 6 months; however, participants in the in-person group gained the least weight. ${ }^{33}$ We believed a priori that participants in the ASPIREGroup arm, who initially experienced twice the weight loss in the first year compared to either ASPIRE-Phone or MOVE!, would have continued to experience greater weight loss than those in the other two programs in the second year-after all, the program components, including the coaches, remained the same.

One possible reason for the higher weight loss in the ASPIRE-Group in the first year is the group cohesion that leveraged social support from peer veterans within the groups. ${ }^{26}$ Although anecdotal, ASPIRE-Group participants expressed concerns to their coaches about reducing the frequency of coaching sessions; based on coaches' feedback, less frequent sessions appeared to impact group cohesion and commitment over time. During the first 3 months, participants had weekly sessions, which then decreased to biweekly and then monthly in the first year; in the second year, sessions were further reduced to every 2 months.

It appears that much of the weight regain seen in the second year was driven by participants with diabetes (Fig. 3) who lost weight in the first 3 months but then started regaining it as sessions became increasingly less frequent. Evidence is emerging of specific regimen-related distress among patients with diabetes, and how this emotional distress has been associated with negative behavioral and health outcomes. ${ }^{34-36}$

Table 3 Weight Change by Time Point and Program

\begin{tabular}{|c|c|c|c|c|c|c|c|}
\hline & \multirow[t]{2}{*}{ Month } & \multirow[t]{2}{*}{ Weight change from baseline } & \multirow[t]{2}{*}{ Lower CI } & \multirow[t]{2}{*}{ Upper CI } & \multicolumn{3}{|l|}{$p$ values: } \\
\hline & & & & & vs. baseline & vs. phone & vs. MOVE! \\
\hline \multirow{4}{*}{$\begin{array}{l}\text { ASPIRE-Phone } \\
n=105\end{array}$} & 3 & -1.66 & -2.88 & -0.44 & 0.007 & & 0.40 \\
\hline & 12 & -1.93 & -3.13 & -0.74 & 0.001 & & 0.47 \\
\hline & 18 & -1.78 & -3.02 & -0.54 & 0.005 & & 0.92 \\
\hline & 24 & -2.13 & -3.43 & -0.83 & 0.001 & & 0.92 \\
\hline ASPIRE-Group & 3 & -2.38 & -3.55 & -1.21 & $<0.001$ & 0.40 & 0.09 \\
\hline \multirow[t]{3}{*}{$n=115$} & 12 & -3.00 & -4.14 & -1.86 & $<0.001$ & 0.21 & 0.04 \\
\hline & 18 & -1.62 & -2.82 & -0.42 & 0.008 & 0.77 & 0.85 \\
\hline & 24 & -1.40 & -2.61 & -0.18 & 0.024 & 0.56 & 0.63 \\
\hline MOVE! & 3 & -0.91 & -2.14 & 0.32 & 0.147 & 0.40 & \\
\hline \multirow[t]{3}{*}{$n=112$} & 12 & -1.32 & -2.48 & -0.16 & 0.025 & 0.47 & \\
\hline & 18 & -1.71 & -2.95 & -0.46 & 0.007 & 0.92 & \\
\hline & 24 & -1.78 & -3.07 & -0.49 & 0.007 & 0.92 & \\
\hline
\end{tabular}




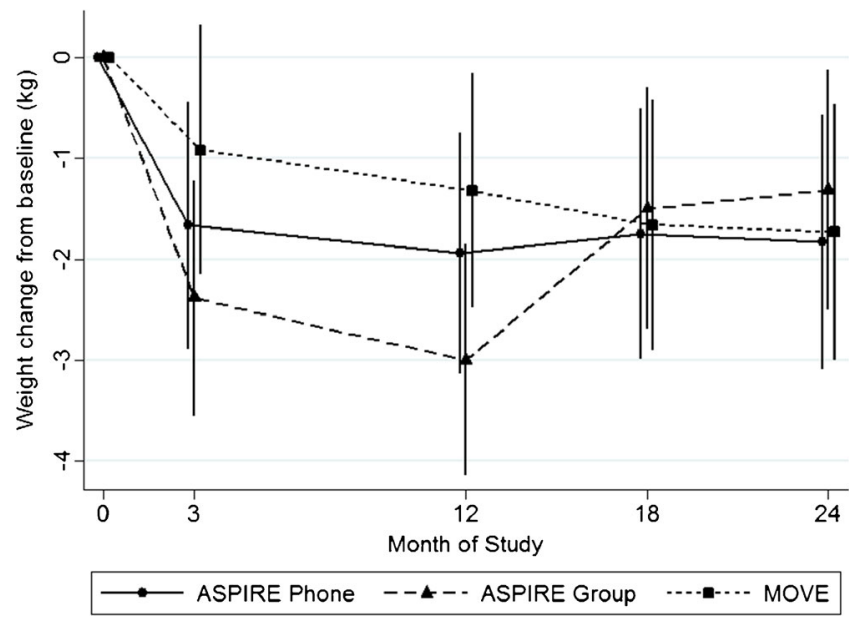

Figure 2 Weight loss across initial treatment and long-term follow-up by group $(n=332)$.

These participants who might have benefited from the social support provided by their groups may have been especially affected by the loss of more frequent group sessions. These findings point to the possibility that participants with diabetes may need longer-term and more intensive treatment, with at least biweekly contact, ${ }^{37}$ in order to maintain weight loss. Because one-third of the patients in the present study had diabetes, and prevalence of the disease is high among VA users overall, ${ }^{38}$ these individuals are an important subgroup in which to address obesity.

Participants in the two SC groups engaged in an almost threefold higher number of sessions across the 24 months, but overall, that difference was attributed to higher participation in the first year. By the second year, all three groups completed fewer than three visits on average. Further research is needed to explore whether offering more sessions over a longer period would help keep participants engaged without breaking connections among peer participants and with interventionists. Additional components, such as refresher groups or focused weight campaigns ${ }^{19}$, more frequent sessions with individual check-ins, and/or a combination of these elements have the potential to enhance long-term weight loss maintenance
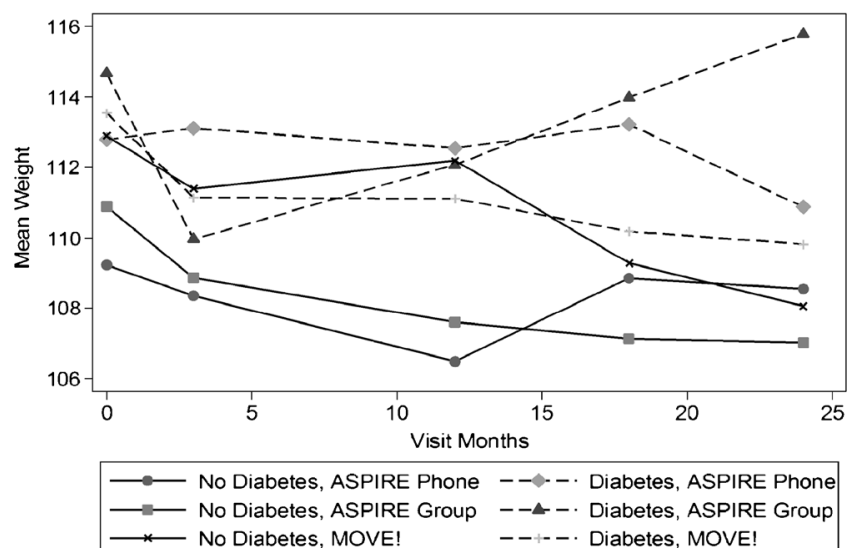

Figure 3 Weight loss and maintenance over time by diabetes status and group. outcomes, especially for individuals with diabetes. These recommendations are offered despite recognition of constrained program resources and capacity limits, in the hope that alternative innovative evidence-based approaches ${ }^{39}$ for engaging veterans in longer-term obesity treatment may be prioritized moving forward. Findings from other published secondary analyses of the ASPIRE-VA trial results suggest that other subgroups of patients, including individuals with pain ${ }^{11}$ or binge eating, ${ }^{40}$ may also benefit from tailored or more intensive weight loss support.

Despite the issues highlighted above, it is important to note that minimal maintenance support (i.e., one contact every other month) appeared to be sufficient to help maintain continued gradual and modest weight loss for participants in the ASPIRE-Phone and MOVE! programs over 2 years (and perhaps for individuals without diabetes within ASPIREGroup). In the VA, nearly $75 \%$ of MOVE! services are delivered via in-person groups. ${ }^{9}$ Although some VA providers and staff believe telephone-based programs are not effective, ${ }^{41}$ our findings and those of previous studies ${ }^{37}$ show that phonebased treatment can promote gradual long-term weight loss and maintenance over 2 years. ${ }^{37}$ Offering this option may improve access for veterans with significant transportation or scheduling issues that limit their ability to come to the VA for treatment. Promising new automated technologies and programs such as TeleMOVE ${ }^{29}$ and online-adapted versions of the Diabetes Prevention Program (DPP) have been piloted ${ }^{42}$ and offer the potential for further expanding treatment delivery options.

Several limitations apply. First, not all participants in the initial ASPIRE-VA trial consented to participate in the second year. Thus, we must be cautious in interpreting our results. However, other than age, results showed that there were no differences, including initial weight loss, between those who consented and those who did not consent to the second year of treatment. Second, there were significant program differences between the two SC programs and the MOVE! program, which varied in its offerings across the two study sites. However, there is wide variability across sites nationally in weight management offerings in usual care. Third, unlike other longterm weight loss trials, ${ }^{37,43}$ we had pragmatic eligibility criteria (e.g., participants were not required to lose $5-10 \%$ of their baseline weight to be eligible to participate in the second year), ${ }^{44}$ thus limiting our ability to assess maintenance of prior clinically significant weight loss. Fourth, we did not randomize patients to programs in the second year. Therefore, this was not a weight-maintenance randomized controlled trial. Fifth, the exploratory analyses that highlight the potential impact of diabetes leading to longer-term weight gain are speculative, because medications used to treat diabetes may facilitate or impede weight loss depending on the regime. Controlling for medication regime is a complex undertaking and is outside the scope of this study. We acknowledge that it may be fruitful to target weight loss treatment to individuals with prediabetes to reduce the incidence of diabetes, ${ }^{45}$ and ultimately to lower the 
currently high prevalence of diabetes; however, we were not able to ascertain prediabetes status among our participants. Lastly, participants in the ASPIRE-VA were on average over 50 years old. With recent deployments to Iraq and Afghanistan winding down, younger veterans comprise an increasing share of the population. Future research is needed to design programs to engage younger veterans in healthy weight loss. ${ }^{9}$

Overall, these findings highlight the need for the VA to provide not only ongoing/continuous care for obesity, ${ }^{24}$ but to have sufficiently frequent contact (at least monthly, or even more frequently for special subgroups including individuals with diabetes) to promote long-term weight loss maintenance. Finally, these findings highlight that phone-based coaching is a viable treatment modality for increasing access. Moving forward, combining evidence from this and other evaluations to date, ${ }^{46-50}$ the VA can continue their leadership in developing effective and cutting-edge population-based initial treatment and long-term continuous-care weight management programs for US veterans.

Acknowledgements: We gratefully acknowledge the ASPIRE-VA study team staff, including Samantha Lindenauer, Lindsay Street, Bradley Youles, along with the Move! program leaders, for their dedication to this program. We would also like to extend a particular acknowledgement to all of the Veterans who participated in this trial. This study was funded by the Department of Veteran Affairs, Health Services Research and Development Grant \#IBB 09-034 and the VA Diabetes QUERI Center. The 24-month outcomes were presented at the Society of Behavioral Medicine conference as an oral presentation in 2014. The views expressed in this presentation are our own and do not reflect the position or policy of the Department of Veterans Affairs or the United States government.

Corresponding Author: Lesley D. Lutes, $\mathrm{PhD}$; Department of PsychologyUniversity of British Columbia, 3187 University Way, Kelowna, BC V1V 1V7, Canada (e-mail: lesley.lutes@ubc.ca).

\section{Compliance with Ethical Standards:}

Conflict of Interest: The authors declare no conflicts of interest.

\section{REFERENCES}

1. Flegal KM, Carroll MD, Kit BK, Ogden CL. Prevalence of obesity and trends in the distribution of body mass index among US adults, 19992010. JAMA. 2012;307(5):491-7.

2. Koepsell TD, Forsberg CW, Littman AJ. Obesity, overweight, and weight control practices in U.S. veterans. Prev Med. 2009;48(3):267-71.

3. Koepsell TD, Littman AJ, Forsberg CW. Obesity, overweight, and their life course trajectories in veterans and non-veterans. Obesity. 2012;20(2):434-9.

4. Department of Veterans Affairs; Department of Defense. VA/DoD clinical practice guidelines for screening and management of overweight and obesity. 2nd vol. Washington: VA Office of Quality, Safety and Value and Clinical Performance Assurance Directorate, United States Army MEDCOM; 2014.

5. Rush T, LeardMann CA, Crum-Cianflone NF. Obesity and associated adverse health outcomes among US military members and veterans: findings from the millennium cohort study. Obesity. 2016;24(7):1582-9.

6. RAND Study Team. Balancing demand and supply for veteran's health care: a summary of three RAND assessments conducted under the Veterans Choice Act. Santa Monica: RAND Corporation; 2016.

7. Kahwati LC, Lewis MA, Kane H, et al. Best practices in Veterans Health Administration's MOVE! Weight Management Program. Am J Prev Med. 2011;42(5):457-64.
8. LeBlanc ES, O'Connor E, Whitlock EP, Patnode CD, Kapka T. Effectiveness of primary care-relevant treatments for obesity in adults: a systematic evidence review for the U.S. Preventive Services Task Force. Ann Intern Med. 2011;155(7):434-7.

9. Kahwati LC, Lance TX, Jones KR, Kinsinger LS. RE-AIM evaluation of the Veterans Health Administrations MOVE! Weight Management Program. Transl Behav Med. 2011;1(4):551-60.

10. Romanova M, Liang L-JL, Deng ML, Li Z, Heber D. Effectiveness of the MOVE! multidisciplinary weight loss program for veterans in Los Angeles. Prev Chronic Dis. 2013; 10:E112-20.

11. Masheb RM, Lutes LD, Kim HM, et al. Weight loss outcomes in patients with pain. Obesity. 2015;23(9):1778-84.

12. Littman AJ, Boyko EJ, McDonell MB, Fihn SD. Evaluation of a weight management program for veterans. Prev Chronic Dis. 2012;9:E99.

13. Perri MG. Effects of behavioral treatment on long-term weight loss: lessons learned from the Look AHEAD trial. Obesity. 2014;22(1):3-4.

14. Wadden TA, Webb VL, Moran CH, Bailer BA. Lifestyle modification for obesity new developments in diet, physical activity, and behavioral treatment. Circulation. 2012;125(9):1157-70.

15. Pagoto SL, Appelhans BM. A call for an end to the diet debates. JAMA. 2013;310(7):687-8.

16. Yancy WS, Mayer SB, Coffman CJ. Effect of allowing choice of diet on weight loss: a randomized trial. Ann Intern Med. 2015;162(12):805-14.

17. MacLean PS, Wing RR, Davidson $\mathbf{T}$, et al. NIH working group project: innovative research to improve maintenance of weight loss. Obesity. 2015;23(1):7-15.

18. Perri MG, Corsica JA. Improving the maintenance of weight lost in behavioral treatment of obesity. In: Wadden TA, Stunkard AJ, ed. Handbook of obesity treatment. New York: Guilford Press; 2002. p. 357-79.

19. The Look AHEAD Research Group. Eight-year weight losses with an intensive lifestyle intervention: the Look AHEAD study. Obesity. 2014;22(1):5-13.

20. Lutes LD, Winett RA, Barger SD, Wojcik JR, Nichols-Richardson S, Herbert WG, Anderson E. Small changes in nutrition and physical activity promotes weight loss and maintenance: three-month evidence from the ASPIRE randomized trial. Ann Behav Med. 2008;35(3):351-7.

21. Lutes LD, Daiss SR, Barger SD, Read M, Steinbaugh E, Winett R. Small changes approach promotes initial and continued weight loss with a phone-based follow-up: nine-month outcomes from ASPIRES II. Am J Health Promot. 2012;26(4):235-8.

22. Damschroder LJ, Lutes LD, Goodrich DE, Gillon L, Lowery JC. A small-change approach delivered via telephone promotes weight loss in veterans: results from the ASPIRE-VA pilot study. Patient Educ Couns. 2010;79(2):262-6.

23. Cummings DM, Lutes LD, Littlewood K, DiNatale E, Hambidge B, Schulman K. EMPOWER: a randomized trial using community health workers to deliver a lifestyle intervention program in African American women with type 2 diabetes: design, rationale, and baseline characteristics. Contemp Clin Trials. 2013;36(1):147-53.

24. Lutes LD, Steinbaugh EK. Theoretical models for pedometer use in physical activity interventions. Phys Ther Rev. 2010;15(3):143-53.

25. Lutes LD, DiNatale E, Goodrich DE, et al. A randomized trial of a small chances approach for weight loss in veterans: design, rationale, and baseline characteristics of the ASPIRE-VA trial. Contemp Clin Trials. 2013;23(7):161-72.

26. Damschroder LJ, Lutes LD, Kirsh S, et al. Small-changes obesity treatment among veterans: 12-month outcomes. Am J Prev Med. 2014;47(5):541-53.

27. Guare JC, Wing RR, Grant A. Comparison of obese NIDDM and nondiabetic women: short- and long-term weight loss. Obesity. 1995;3(4):329-35.

28. Schwartz MW, Porte D. Diabetes, obesity, and the brain. Science. 2005;307(5708):375-9.

29. Skoyen JA, Rutledge T, Wiese JA, Woods GN. Evaluation of the teleMOVE: a telehealth weight reduction intervention for veterans with obesity. Ann Behav Med. 2015;49(4):628-33.

30. Jensen MD, Ryan DH, Apovian CM, et al. 2013 AHA/ACC/TOS guideline for the management of overweight and obesity in adults. J Am Coll Cardiol. 2014;63(25):2985-3025.

31. Balk EM, Earley A, Raman G, Avendano EA, Pittas AG, Reington PL. Combined diet and physical activity promotion programs to prevent type 2 diabetes among persons at increased risk: a systematic review for the Community Preventive Services Task Force. Ann Intern Med. 2015; 163(6):437-55.

32. Wadden TA, Butryn ML, Hong PS, Tsai AG. Behavioral treatment of obesity in patients encountered in primary care settings: a systematic review. JAMA. 2014;312(17):1779-91. 
33. Svetkey LP, Stevens VJ, Brantley PJ, et al. Comparison of strategies for sustaining weight loss: the weight loss maintenance randomized controlled trial. JAMA. 2008;299(10):1139-48.

34. Cummings DM, Lutes L, Littlewood K, et al. Regimen related distress, medication adherence, and glycemic control in rural African American women with type 2 diabetes mellitus. Ann Pharmacother. 2014;48(8):970-7.

35. Fisher L, Mullan JT, Arean P, Glasgow RE, Hessler D, Masharani U. Diabetes distress but not clinical depression or depressive symptoms is associated with glycemic control in both cross-sectional and longitudinal analyses. Diabetes Care. 2010;33(1):23-8.

36. Fisher L, Glasgow RE, Strycker LA. The relationship between diabetes distress and clinical depression with glycemic control among patients with type 2 diabetes. Diabetes Care. 2010;33(5):1034-6.

37. Perri MG, Limacher MC, Durning PE, et al. Extended-care programs for weight management in rural communities: the Treatment of Obesity in Underserved Rural Settings (TOURS) randomized trial. Arch Intern Med. 2008; 168(21):2347-54.

38. Lynch CP, Strom JL, Egede LE. Effect of Veterans Administration use on indicators of diabetes care in a national sample of veterans. Diabetes Technol Ther. 2010;12(6):427-33.

39. Ahern J, Worthen M, Masters J, Lippman SA, Ozer EJ, Moos R. The challenges of Afghanistan and Iraq veterans; transitions from military to civilian life and approaches to reconnection. PLoS One. 2015;10(7): 1-13.

40. Masheb RM, Lutes LD, Kim HM, et al. High frequency binge eating predicts weight gain among veterans receiving behavioral weight loss treatments. Obesity. 2015;23(1):54-61.

41. Arigo D, Hookere S, Funderburk J, et al. Provider and staff perceptions of veterans' attrition from a national primary care weight management program. Prim Health Care Res Dev. 2015;16(2):147-56.
42. Moin T, Mangione CM. Live vs electronically delivered weight-loss intervention: paying for feasible interventions. JAMA Intern Med. 2014;174(7): 1157-9.

43. Wing RR, Tate DF, Gorin AA, Raynor HA, Fava JL. A self-regulation program for maintenance of weight loss. N Engl J Med. 2006;355(15):1563-71.

44. Thomas JG, Bond DS, Phelan S, Hill Jo, Wing RR. Weight-loss maintenance for 10 years in the National Weight Control Registry. Am J Prev Med. 2014;46(1):17-23.

45. Knowler WC, Barrett-Connor E, Fowler SE, et al. Reduction in the incidence of type 2 diabetes with lifestyle intervention or metformin. N Engl J Med. 2002;346(6):393-403.

46. Jay M, Mateo KF, Squires AP, Kalet AL, Sherman SE. Military service and other socioecological factors influencing weight and health behavior change in overweight and obese veterans: a qualitative study to inform intervention at the United States Veterans Health Administration. BMC Obesity. 2016;3(5):2-14.

47. Littman AJ, Damschroder LJ, Verchinina L, et al. National evaluation of obesity screening and treatment among veterans with and without mental disorders. Gen Hosp Psychiatry. 2015;37(1):7-13.

48. Locatelli SM, Sohn M-W, Spring B, Hadi S, Weaver FM. Participant retention in the Veterans Health Administration's MOVE! weight management program, 2010. Prev Chronic Dis. 2012;9:E129.

49. Angel C, Armstrong NJ. Enriching veterans' lives through an evidence based approach: a case of team red, white \& blue. Syracuse: Institute for Veterans and Military Families, Syracuse University; 2016.

50. Spring B, Sohn M-W, Locatelli SM, Kahwati L, Weaver FM. Individual, facility, and program factors affecting retention in a national weight management program. BMC Public Health. 2014;14(363):4-11. 